\title{
DOCENTES DE ESCOLAS PÚBLICAS DIANTE DE PRÁTICAS DISCRIMINATÓRIAS NO COTIDIANO ESCOLAR
}

\author{
José Bonifácio Alves da Silva \\ Gicele Maria Cervi
}

\section{Resumo}

O presente artigo traz um entendimento das práticas discriminatórias no cotidiano escolar que permeiam os currículos e de como os docentes entrevistados se posicionam diante delas. $\mathrm{O}$ texto resulta da análise de seis entrevistas semiestruturadas realizadas com docentes atuantes no ensino fundamental e no ensino médio de quatro escolas públicas de Blumenau-SC. Observa-se que há discriminações referentes ao desempenho escolar, à classe, à aparência física, ao gênero, sexualidade e raça/etnia. Docentes entrevistados se posicionam como elaboradores de estratégicas e inesperadas táticas pedagógicas de enfrentamento às discriminações e exclusões que permeiam os cotidianos escolares, propondo para isso tarefas, projetos de intervenção e ações inclusivas, mesmo que sejam limitadas.

Palavras-chave: cotidiano escolar; discriminações; currículo.

\section{PUBLIC SCHOOL TEACHERS ON DISCRIMINATORY PRACTICES AT SCHOOL ROUTINE}

\begin{abstract}
This paper aims to reflect on discriminatory practices at the school routine that permeate schools' curricula and how teachers involved in the study pose before them. It results from an analysis of six semi-structured interviews conducted with elementary and high school teachers from four public schools of Blumenau city, in the state of Santa Catarina, Brazil. We note there is some discriminatory practices towards school performance, class, physical appearance, gender, sexuality and race/ethnicity. Teachers we have interviewed elaborate strategies and unexpected pedagogical tactics for facing discrimination and exclusion attitudes that permeate school routines, proposing tasks, intervention projects, and inclusive actions, though they are limited.
\end{abstract}

Keywords: school routine; discrimination practices; curriculum.

\section{DOCENTES DE ESCUELAS PÚBLICAS DELANTE DE LAS PRÁCTICAS EN EL COTIDIANO ESCOLAR}

Resumen

El presente artículo trae un entendimiento de las prácticas discriminatorias en el cotidiano escolar que atraviesan los currículos y cómo los docentes entrevistados se posicionan ante estas discriminaciones. El texto resulta del análisis de seis entrevistas semiestructuradas realizadas con docentes actuantes en la enseñanza primaria y secundaria de cuatro escuelas públicas de Blumenau-SC. Observase que hay discriminaciones, referentes al desempeño escolar, a la clase, a la apariencia física, al género, a la sexualidad y a la raza/etnia. Los docentes entrevistados se posicionan como aquellos que elaboran estratégicas e inesperadas tácticas pedagógicas de enfrentamiento a las discriminaciones y exclusiones que atraviesan los cotidianos escolares, proponiendo, por lo tanto, tareas, proyectos de intervención y acciones inclusivas, aunque sean limitadas.

Palabras clave: cotidiano escolar; discriminaciones; currículo. 


\section{SITUANDO O TEXTO}

$\mathrm{Na}$ sociedade, as demarcações hierarquizadas das diferenças entre os sujeitos geram práticas discriminatórias com efeitos concretos ligados aos acessos desiguais aos recursos materiais e simbólicos. Fronteiras culturais delimitam diferenças, mas também a existência dos incluídos e dos excluídos. Separam os adequados dos não enquadrados aos padrões hegemônicos de normalidade, os quais têm impactos nos currículos escolares ${ }^{1}$. Percursos curriculares são afetados por inferiorizações de maneiras de ser.

O presente artigo traz um entendimento de como os docentes de escolas públicas se posicionam diante das práticas discriminatórias no cotidiano escolar que permeiam os currículos. Para isso, busca identificar as práticas discriminatórias no cotidiano escolar e compreender como os docentes entrevistados se posicionam diante dessas práticas.

Neste texto, a discussão sobre as discriminações de sujeitos possibilita pensar, em alguma medida, na intersecção entre as desigualdades étnico-raciais, de classe, gênero e sexualidade, às quais, em determinadas circunstâncias, não ocorrem separadamente. Existem pessoas vivendo "[...] vários processos desiguais simultaneamente". (OLIVEIRA, 2009, p. 159).

As discriminações ocorrem de maneiras específicas para os diferentes grupos e dependem dos contextos, além de serem interseccionadas como manifestações de opressões. Pessoas de diferentes grupos encaram e se resignam diante das discriminações de diferentes modos. "Todas essas expressões de diferenças ou de especificidades têm manifestações próprias para o universo feminino e para o masculino, que são transversalizadas pela condição de classe, de raça, religiosa, etc.”. (BANDEIRA, BATISTA, 2002, p. 135). Não há nenhuma categoria genérica que comporte todas as formas de discriminação. De acordo com a situação, um aspecto inferiorizado conta mais do que outros e/ou do que uma característica valorizada.

Acontecem muitos processos opressivos sofridos pelas alteridades culturais, étnico-raciais, femininas, sexuais, pessoas com deficiência, entre outras, articulados às questões de classe, mas não restritos a estas. "A lista da alteridade excluída é cada vez mais extensa, inacabável". (SKLIAR, 2001, p. 16). As desigualdades foram multiplicadas, complexificadas e outras fronteiras da exclusão foram produzidas. É importante enfatizar que dentro dos grupos discriminados também se manifestam diversas discriminações.

Proliferam as formas de convivência, conformismo, resistência e negociação nas relações com as desigualdades. Também "[...] as fronteiras da exclusão aparecem, desaparecem e voltam a aparecer, se disfarçam; seus limites se ampliam, mudam de cor, de corpo, de nome e de linguagem". (SKLIAR, 2001, p. 14). Inferiorizados são muitas vezes valorizados parcialmente, porque as opressões atingem diferentes aspectos da vida, quando se é adequado em uns, é-se discriminado em outros. Configuram-se contextos de discriminações, exclusões, adequações e inclusões parciais e subordinadas.

Na presente reflexão, compreendemos algumas repercussões dessas questões na escola por meio de teorizações colaboradoras na percepção das formas de discriminação de sujeitos que permeiam o cotidiano escolar e na análise de falas de professores entrevistados acerca desta questão.

\footnotetext{
${ }^{1}$ Emprega-se o plural devido às múltiplas maneiras de se pensar e fazer o currículo escolar.
} 


\section{ATRAVESSAMENTOS METODOLÓGICOS}

Construímos uma compreensão dos posicionamentos acessados referente à atuação de docentes e discentes no desenvolvimento dos currículos quanto às formas de discriminação de sujeitos na escola. Para isso, utilizamos informações extraídas da análise de entrevistas semiestruturadas realizadas no segundo semestre de 2018 com 6 professores de diferentes disciplinas atuantes no ensino fundamental e no ensino médio de quatro escolas públicas de Blumenau, Santa Catarina.

Os assuntos tratados nas entrevistas versavam sobre o entendimento de currículo escolar, as tensões sociais implicadas no cotidiano da escola, a preocupação de tratar de temas relacionados ao cotidiano de estudantes, os objetivos da formação escolar, a percepção das diferenças entre os sujeitos escolares, as necessidades de alterações curriculares no dia a dia e as formas de discriminação que emergem como problemas a serem trabalhados na sala de aula.

Considerou-se que o manejo da entrevista "[...] pode contribuir para que a fala surja o mais próximo de um sentido convergente e delimitado, ou promover a abertura, experiência de indecidibilidade, contribuindo para movimentar as questões". (TEDESCO, SADE, CALIMAN, 2013, p. 308). As entrevistas estiveram abertas às falas sobre as experiências de atuação cotidiana na sala de aula. Nelas, questões enfrentadas no trabalho docente emergiram. Uma destas questões é o foco deste artigo.

Aqui, vale enfatizar igualmente os limites da pesquisa, pois "[...] os cotidianos estão pulsando mais fortemente do que qualquer produção de sentidos que possamos fazer em nossas pesquisas 'com' os seus sujeitos praticantes”. (FERRAÇO, ALVES, 2015, p. 315). Reconhecemos a nossa visão, audição e sensibilidade limitadas em perceber múltiplas produções de sentidos para a educação escolar no seu cotidiano. Conseguimos fazer leituras contingentes de fragmentos de realidades educacionais num exercício de articulação das informações produzidas a fim de mostrar uma coesão e uma coerência que possam ser reconhecidas na abordagem.

As entrevistas com os professores participantes ${ }^{2}$ tinham um roteiro estabelecido, mas também foram guiadas pelas questões que surgiram nos momentos em que aconteceram. Muitas vezes expectativas e perguntas foram reelaboradas por causa das questões apontadas pelos colaboradores deste estudo.

Seguimos as direções indicadas pelas entrevistas sob o efeito das questões emergentes na investigação. $\mathrm{O}$ método analítico empregado consistiu "[...] em dar visibilidade às relações que constituem uma dada realidade, na qual o pesquisador se encontra enredado". (BARROS, BARROS, 2013, p. 376). Houve um envolvimento, ainda que parcial, com a investigação e a produção de informações.

A seguir, apresentamos o nosso entendimento articulado com algumas teorizações sobre o currículo (SILVA, 2000; LOPES, MACEDO, 2011; FERRAÇO, CARVALHO, 2012), que possibilitam perceber as formas discriminatórias em percursos curriculares na análise interpretativa realizada a partir dos posicionamentos de docentes de escolas públicas de Blumenau.

\footnotetext{
2 Usamos pseudônimos para identificar as falas.
} 


\section{OS CURRÍCULOS E AS PRÁTICAS DISCRIMINATÓRIAS NO COTIDIANO ESCOLAR}

Os currículos escolares estão relacionados com os cursos das disciplinas, das avaliações, do tempo nos espaços, das ordenações, seleções de conteúdo, etapas, atividades, programações, experiências de uma formação, mas também com os cursos das políticas, gestões, dos parâmetros e diretrizes que impactam nessa formação. Dinâmicas culturais e políticas operam no exterior e interior da escola contemporânea, afetando os currículos escolares.

Os cotidianos das escolas não estão descolados dos seus contextos, os quais são marcados pelas desigualdades, preconceitos e discriminações. Esses contextos compõem a escola, mas também as tensões entre as expectativas depositadas nela e as circunstâncias das possibilidades com as quais lida.

Nesse sentido, a professora Luiza contou que o bairro da escola em que trabalha é considerado perigoso, por causa do comércio de drogas ilícitas: "Tem muita droga aqui. [...] Tem uma questão de abandono social, tem uma questão de discriminação". Preconceitos e discriminações têm implicações concretas na vida das pessoas, regiões, bairros e instituições estigmatizadas.

Os preconceitos são formas de conhecer através de estereótipos, estigmas e padrões estabelecidos para compreender e identificar. "Todas as formas de conhecer o outro, a alteridade, passam, necessariamente, pelo preconceito, em razão de que o eu não pode jamais se apropriar do outro, daquele que representa a diferença”." (BANDEIRA, BATISTA, 2002, p. 129). Tentamos desviar dos preconceitos e expurgá-los, mas não conseguimos.

Nos cotidianos, o que conseguimos perceber, por maiores que sejam os nossos esforços, são representações preconceituosas, porque não conseguimos captar compreensões puras, completas, imparciais e desinteressadas dos outros. Somos atravessados pelas circunstâncias que nos constituem e que constituem as nossas percepções. "Valemo-nos, portanto, de juízos provisórios [como se não fossem provisórios] que serão refutados a partir do momento em que não mais nos capacitarem à orientação e à ação". (PATTO, 1993, p. 126).

Os preconceitos tentam apreender os outros e contê-los nos estereótipos (imagens congeladas). Alimentam a discriminação constantemente quando classificamos os sujeitos. Resultam de racionalizações dos outros que geram discriminações. O desafio consiste em perceber quando há injustiças nesse processo favorecendo as desigualdades.

Para Bandeira e Batista (2002, p. 133), "[...] a imagem de alguém sempre tem algum signo de poder". O poder de dizer quem é, mesmo temporariamente, o outro sob maneiras limitadas de conceber a alteridade, ainda que não pareçam. Apesar de parecerem fixos, os estereótipos precisam ser reiteradamente fixados. Aí reside sua ambivalência, fundamentando preconceitos e discriminações. (BHABHA, 1998).

Discriminações distinguem e podem restringir a distribuição de recursos e os acessos a determinados locais da sociedade. Por isso existem aqueles que escondem suas diferenças em relação aos padrões hegemônicos. Ainda precisamos de mais "[...] compreensão dos processos de subjetivação tornados possíveis (e plausíveis) através do discurso do estereótipo". (BHABHA, 1998, p. 106).

Ocorrem disputas contínuas por mais vantagens simbólicas que podem gerar mais vantagens materiais em diferentes espaços sociais, inclusive nas escolas. Quanto ao desempenho escolar, a disputa acontece para não estar entre os atrasados, os quais são discriminados e cobrados para acompanhar o ritmo considerado adequado. "Tem a grade ali e a gente tem que cumpri-la, não pode ficar esperando, por aquele aluno que está atrasado, aquele que está mais adiantado". 
(Professor Ciro). Avaliações premiam e ranqueiam os que acompanham o ritmo padrão para serem categorizados como bons alunos, posicionando-os na frente e acima dos desinteressados, problemáticos, atrasados e maus alunos.

O simbólico se entrelaça com o material para moldar a vida. Por isso, precisamos pensar tanto sobre a dimensão simbólica quanto sobre a dimensão material e as articulações entre estas dimensões para alterar, em alguma medida e de alguma forma, duras realidades, dolorosamente marcadas pelas desigualdades, injustas discriminações, preconceitos e estereotipações.

Circunstâncias simbólicas e materiais atravessam e produzem as posições dos sujeitos. Questões econômicas não envolvem somente o simbólico, mas necessitam ser significadas no âmbito do simbólico que tem implicações concretas. (HALL, 1997). É indesejável estar em desvantagem e ter prejuízos nas relações sociais.

Pessoas do bairro da escola em que a professora Luiza, o professor Ciro e a professora Manuela atuam são discriminadas por ser um local de população de baixa renda, por haver relativamente muitos negros, imigrantes oriundos do Haiti, e por ser considerado um local com alto índice de criminalidade. Segundo a professora Luiza, há problemas no atendimento de serviços públicos. Problemas da comunidade escolar impactam os estudantes e professores, afetam os sujeitos de diversos modos.

A representação racista do negro como suspeito, sem a devida análise das condições socioeconômicas que produzem o aumento do envolvimento de pessoas com o tráfico de drogas, contribui para associarem o bairro como um lugar perigoso de Blumenau. "Cara, droga tem ali na frente do outro colégio [cita o nome de outra escola pública], mas ninguém associa. Será que é por que lá é lugar de branco e aqui é de negro?” (Professora Luiza).

Outra docente da escola em que a professora Luiza atua falou da ocorrência de discussões acerca dos estigmas desse bairro. "Eles têm alguns estigmas que a gente tenta trabalhar para não reforçar e trabalhar também os aspectos positivos que acabam influenciando na estima deles". (Professora Manuela). Tais estigmas relacionam-se com representações pejorativas do local e de seus moradores, associando-os à marginalidade, à criminalidade e ao tráfico de drogas. Há uma atuação docente no sentido de agregar ao currículo ações de combate às estigmatizações inferiorizantes.

Apesar de discussões acerca dos estigmas, preconceitos e discriminações, muitas vezes, não estarem previstas no currículo prescrito, ocasionalmente elas acontecem (como mostrado adiante aqui). Para além das grades curriculares, que ainda prendem, há liberdade relativa em ações inesperadas, reelaborando currículos. "Sendo assim, pode-se dizer que existem muitos currículos em ação nas escolas, apesar dos diferentes mecanismos homogeneizadores". (FERRAÇO, CARVALHO, 2012, p. 10).

O percurso formativo prescrito com conteúdos, períodos e etapas é redefinido de inúmeras e diferentes maneiras nas múltiplas práticas escolares cotidianas. Relações, circunstâncias, contextos e necessidades reconfiguram o currículo a partir de onde e com quais sujeitos este acontece, sem deixar de ter impactos das políticas governamentais e estatais.

Adotamos uma concepção de currículo como significante, prática e âmbito de significação. (SILVA, 2000; LOPES, MACEDO, 2011; FERRAÇO, CARVALHO, 2012; OLIVEIRA, 2013). Entendemos ele como um processo pedagógico direcionador vinculado a uma orientação social, sendo, por isso, permeado pelo poder e pela disputa referentes ao próprio direcionamento das políticas de dentro e de fora da escola. "A perspectiva hegemônica a respeito da escola e àquilo que nela deveria acontecer fundamenta-se em critérios de padronização". (OLIVEIRA, 2013, p. 376). Contudo, esbarra na impossibilidade de completa padronização, pois há diferenciações nas práticas. 
Os cotidianos escolares possuem rituais que procuram balizar as rotinas estabelecidas. Mesmo não sendo somente repetições, existem princípios bastante reiterados ou trazidos de maneira atualizada, que são sustentados por preconceitos e afetam as seleções, definições e ações cotidianas, ainda que preliminarmente.

Baseadas em ênfases e omissões de conteúdo, disciplinas, diretrizes, parâmetros e dispositivos educacionais, as seleções configuram o currículo escolar e estabelecem “[...] o conhecimento técnico e acadêmico legitimado por relações de poder mediadas pelos órgãos oficiais do Estado - avaliações centralizadas nos resultados, livros didáticos, propostas curriculares oficiais". (LOPES, MACEDO, 2011, p. 84).

Frequentemente as seleções dos currículos escolares discriminam os conhecimentos desvalorizados pela economia de mercado. Nesses processos, certos conhecimentos são valorizados pelas instituições de ensino porque estes têm prestígio social e possibilitam vantagens materiais e simbólicas. "É nesse contexto que se estruturam práticas curriculares com organização seletiva, privilegiando determinados conteúdos, além de excluir e silenciar referências históricas [e culturais] de parcela significativa dos estudantes que atende". (BRITO, MACHADO, 2018, p. 269).

Conhecimentos mais valorizados pelos currículos, os cânones eurocêntricos e conteúdos que representam a suposta alta cultura normalizadora são os que contribuem para a manutenção de hierarquizações existentes, mantenedoras da ordem desigual capitalista e discriminadora. Tratase de uma discriminação, por vezes, planejada e mantida pela tradição seletiva dos currículos escolares. (BRITO, MACHADO, 2018). Os conteúdos canônicos dos currículos superiorizam valores que, supostamente, deveriam ser buscados e cultivados por todos.

A seletividade em favor das desigualdades torna mais suscetível que inferiorizações histórica e culturalmente construídas sejam presenciadas nas escolas. Não interessa à naturalização da desigualdade na sociedade capitalista, em favor da competição, que efeitos de processos passados presentes em elementos configuradores de realidades educacionais, na forma de símbolos de domínio e de subalternidade, sejam discutidos, pois perturbam o status quo.

O reconhecimento, como privilegiados, de alguma maneira, pelas relações desiguais de poder (por ser homem e/ou branco, e/ou quase branco, e/ou heterossexual, e/ou provido de recursos etc.) pode abalar egos cotidianamente enredados na meritocracia. Os outros nos contatos conosco podem nos fazer reconhecer nossos privilégios - desde que haja a construção de sensibilidades em ambientes propícios.

As aparências físicas são associadas à (des)qualificação das capacidades dos sujeitos. "Ao trazer com muita força as características do corpo, o preconceito vai além de uma narrativa, criando uma percepção, formulando uma representação. Cria-se uma ideia - a imagem do outro". (BANDEIRA, BATISTA, 2002, p. 133).

$\mathrm{Na}$ escola, os atravessamentos sociais e culturais produzem a fronteira naturalizada entre o normal e o anormal - delimitando o dentro e o fora da norma -, de acordo com preconceitos que afetam convivências e, frequentemente, geram discriminações. "Eles se agridem verbalmente e, de certa forma, não têm noção do teor do que eles estão falando, do que eles estão fazendo e das proporções que aquilo vai tomar. A escola precisa ter um posicionamento bem sério com relação a isso". (Professora Sandra). Mesmo involuntariamente, sujeitos escolares discriminam muito os outros pelos seus aspectos corporais.

Padrões corporais naturalizados submetem os sujeitos nas relações. Os racismos e os sexismos "[...] frequentemente funcionam por meio de referências a características corporais e, portanto, por meio de referências a supostas certezas biológicas". (KERNER, 2012, p. 46). Requerem naturalizações de supostas inferioridades como certezas atemporais ou que se prolonguem ao longo do tempo. 
$\mathrm{Na}$ sociedade, a aparência é associada à competência para concorrer nas disputas por posições de prestígio. As escolas também são afetadas pelos padrões hegemônicos de beleza e normalidade. "Tem um menino que é muito gordão lá e sofre muito. A galera, toda hora, zoa o cara, entendeu?" (Professor Fernando). Ainda são pouco discutidos a produção e os impactos das classificações através de sentidos agregados às características dos corpos dos sujeitos para discriminar. (BANDEIRA, BATISTA, 2002).

Há hierarquizações ligadas às aparências físicas, mas também às situações dos sujeitos na sociedade a depender do contexto: desempenhos, local onde moram, poder aquisitivo, grupos com os quais se identificam etc. "Ou, por exemplo, a questão racial também. A gente tem. Não dá para dizer que não tem. Tem. A gente está na sala de aula e vê constantemente isso". (Professora Sandra). Determinadas intersecções de diferenças podem fazer com que uns sejam percebidos e/ou se percebam como melhores do que os outros nas salas de aulas.

De acordo com a professora Sandra, "[...] o preconceito com relação ao homossexual a gente vê muito ainda [na escola]. O mais curioso é que isso começa como uma brincadeira". As discriminações pejorativas se manifestam por meio de brincadeiras que disfarçam o racismo, a homofobia e o machismo, entre outras dinâmicas discriminatórias.

Muitas vezes é difícil perceber as práticas discriminatórias sendo expressas em piadas, apelidos e brincadeiras. "Por mais que eles dizem assim: 'Não, ele é meu amigo, eu estou brincando'. [...] Mesmo brincando, é uma forma de eles exteriorizarem”. (Professora Manuela). A sensibilidade para perceber brincadeiras que ridicularizam o outro não está sempre ativa, porque inferiorizações foram naturalizadas nos âmbitos das desigualdades.

A naturalização das práticas discriminatórias, sustentadas por preconceitos, faz com que não percebamos agressões variadas sofridas por mulheres, negros, indígenas, pessoas com orientações sexuais subalternizadas, entre outros, a depender do contexto. "Portanto, pensar o preconceito nos parece indispensável, uma vez que esse pode se constituir em fonte de violência" (BANDEIRA, BATISTA, 2002, p. 120) em relacionamentos que menosprezam diferenças, convertendo-as em inferioridades e desigualdades. Diferenças podem ser concebidas no cotidiano escolar como danosas porque não correspondem aos padrões. Por meio de preconceitos, constituem-se discriminações.

Entre os estudantes, criam-se sentimentos de identificação, pertença e estranhamento a determinados grupos. A exclusão "[...] é um mecanismo de poder centralizador que consiste em proibir pertencimentos [em seleções para acesso a determinados espaços e grupos] e atributos aos outros [em desqualificações]" (SKLIAR, 2003, p. 92). A vontade de estar apenas entre pessoas semelhantes e a exclusão dos diferentes é alimentada pelos preconceitos e discriminações. Os indesejáveis são desejáveis onde são situados por classificações hierarquizadas para conservar sujeitos em vantagem nas relações.

Essas inclusões e exclusões “[...] muitas vezes não indicam apenas diferenças ou singularidades, mas relações hierárquicas e poderes de raiz histórica com atributos fundadores" (BANDEIRA, BATISTA, 2002, p. 131) localizados nos processos de invenção das desigualdades. Discriminações e preconceitos, simultaneamente geradores de inclusão e de exclusão em categorias, estabelecem os belos e os feios, os inteligentes e os ignorantes, os bons e os maus, os confiáveis e os suspeitos. Desqualificam os outros e negam a alteridade como atributo de todos os sujeitos. "É a negação do estar dentro [do padrão de normalidade] que serve, ao mesmo tempo, como uma afirmação desse espaço dentro [da normalidade]". (SKLIAR, 2003, p. 93).

Nessa dinâmica, diversos preconceitos e atitudes discriminatórias acabam sendo expressos em aulas retratadas nas entrevistas. "Tu vês na hora de fazer trabalhos, eles não se misturam. Tu tens sempre que estar intervindo. Têm sempre uns que ficam excluídos”. (Professora Luiza). Uma 
seletividade opera nesses casos, distinguindo os preferidos dos indesejáveis aos grupos formados para a execução de tarefas em coletivos. Alguns professores intervêm nessa seletividade dos estudantes, às quais carregam preconceitos e discriminações, com a finalidade de manter um ambiente mais acolhedor e com menos exclusão de pessoas na trajetória curricular.

\section{ENFRENTAMENTOS ÀS DISCRIMINAÇÕES NAS ESCOLAS}

Os professores entrevistados atuam como reelaboradores do currículo nas práticas e relações nas salas de aulas. Isto porque criam estratégias e táticas cotidianas inesperadas dentro daquilo que percebem como possível, na busca por trabalharem temas considerados relevantes e atenderem algumas expectativas de formação. "Acho que o currículo oficial talvez não seja muito o professor [que interfere], mas na prática acaba sendo, acaba intervindo". (Professora Manuela).

Certeau (1994) diferencia estratégia e tática, afirma que a racionalização estratégica está ligada ao cálculo ou manipulação das forças em um local circunscrito, à gestão das relações com alvos e ameaças. A estratégia "[...] permite capitalizar vantagens conquistadas, preparar expansões futuras e obter assim para si uma independência em relação à variabilidade de circunstâncias". (CERTEAU, 1994, p. 99). Formata o local (in)apropriado para uma determinada finalidade.

A tática é a ação que não depende de um local apropriado, mas depende das circunstâncias para surgir. Joga com aquilo que lhe é imposto. No improviso imprevisto, a tática "[...] tem que utilizar, vigilante, as falhas que as conjunturas particulares vão abrindo na vigilância do poder proprietário". (CERTEAU, 1994, p 101). Opera por lances momentâneos, aproveitando as ocasiões sem conservar o que ganha. Introduz a surpresa em uma ordem como a arte daquele que por esta é submetido.

Docentes ficam entre cumprir as imposições dos planejamentos estratégicos (feitos dentro e fora da escola por eles e outros) e questionar e recriar os sentidos de sua prática. "Têm coisas que eu vou adequar e têm coisas que eu não consigo adequar, que não se encaixam mais". (Professora Sandra). Muitas vezes, as estratégias pedagógicas, planejadas com antecedência, não são suficientes por causa do imprevisível emergente no cotidiano das escolas e das salas de aulas.

A docência utiliza táticas cotidianas elaboradas no momento do trabalho. Além de estratégias pelas tentativas de administração curricular, a docência cria constantemente táticas que têm "[...] constantemente que jogar com os acontecimentos para os transformar em "ocasiões" (CERTEAU, 1994, p. 47) a partir do contexto e das condições da escola.

A professora Manuela salientou a solidariedade mobilizada na escola: "Fora as campanhas [para arrecadação de algo na escola que falta para pessoas da comunidade], às vezes os professores em particular: 'Ah, Fulano de Tal não tem isso, alguém tem? Como a gente pode ajudar?’' Seja para arrecadar agasalhos, dinheiro para a passagem de ônibus de um estudante, seja para viabilizar uma prática curricular com os alunos, ocasionalmente agentes se mobilizam e dão algum suporte material ao percurso formativo de sujeitos escolares.

Buscando contribuir com currículos mais voltados às comunidades constituidoras das escolas, estratégias e táticas inesperadas são utilizadas pelos sujeitos de escolas públicas que revezam o uso da sala de informática, do projetor multimídia, articulam-se em tarefas pedagógicas com as pessoas das escolas e dos entornos delas, vão conhecer outros espaços fora dos muros escolares, utilizam recursos próprios e se põem à procura de outros para efetivar atividades propostas.

Em meio às dificuldades e necessidades, sujeitos de escolas públicas inesperadamente se mobilizam em iniciativas recriadoras do currículo por incluírem o que, a princípio, não estava e reverem aquilo que já estava previsto, recontextualizando segundo as situações vivenciadas, 
enfrentando, com maior e menor intensidade, as faltas de recursos nas escolas públicas, as discriminações e as desigualdades sociais. Para o professor Fernando: "Os alunos trazem conflitos que a escola pode resolver. Têm conflitos que estão para além da escola, onde a escola não vai conseguir atuar, alguns que a escola poderia atuar, mas o poder público não viabiliza a atuação, entendeu?"

Um exemplo de atividade diferenciada que trouxe uma mobilização coletiva inesperada em torno de debates referentes às desigualdades, preconceitos e discriminações à tona foi dado pela professora Benedita. A docente mencionou que fez um trabalho com os estudantes de duas turmas do $9^{\circ}$. ano do ensino fundamental sobre figuras de linguagem, poesia concreta, a expressão de sensibilidade e valores por meio das palavras. Ela e os alunos elencaram várias palavras na aula. "A gente seguiu várias palavras que, de certa forma, levam a alguma reflexão para melhorar o ser humano, nesse sentido". (Professora Benedita).

Cada dupla de alunos organizada para o trabalho expôs os cartazes na escola. Durante a

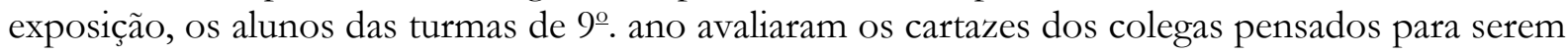
outdoors e votaram naqueles que mais gostaram, seguindo a tarefa solicitada pela professora Benedita, que mencionou na entrevista: "O mais votado foi o da $\mathrm{Y}$ e da $\mathrm{X}$, aquele que está a igualdade e a desigualdade, sobre a sociedade igualitária".

As lutas pela igualdade e por sociedades mais democráticas envolvem o reconhecimento e o atendimento justo de diferenças mutantes e híbridas na escola. Entre elas estão diferenças culturais, étnico-raciais, de gêneros, de sexualidades e outras. Tais diferenças contestam padrões hegemônicos de normalidade ao apresentarem outros modos de ser e possibilidades de identificação.

A construção de uma sociedade mais democrática requer o reconhecimento dos grupos marginalizados, de suas justas demandas e o engajamento em projetos que contribuam para a redução das desigualdades. "Uma revolução, portanto, só o é quando se dá na vida cotidiana, quando são atendidos revolucionariamente os carecimentos radicais. A revolução passa, portanto, pela subjetividade, pela participação". (PATTO, 1993, p. 132).

A tendência ainda presente de superiorizar a brancura, a heterossexualidade, a masculinidade e outros padrões de uma suposta normalidade alimenta as injustiças, o machismo, a intolerância, o racismo, as agressões e os sofrimentos. As representações de raça, classe, sexualidade e gênero - entre outras - resultam de disputas tensas em torno de significações, entre movimentos progressistas e (neo)conservadores da sociedade, as quais têm impactos nos currículos escolares.

Nas mensagens contidas em cartazes pendurados no pátio da escola ${ }^{3}$, referentes a atividade solicitada pela professora Benedita, havia manifestações de repúdio à intolerância, ao preconceito e às discriminações inferiorizantes, entre outras questões que podem ser destacadas em leituras dos trabalhos dos estudantes. "Quando apareceram com a efetivação do trabalho ali, aquele [cartaz] de toda forma de amar, aquele do LGBT, o grandão ali. Eu achei bonita a manifestação deles". (Professora Benedita).

Manifestações sensíveis às sexualidades subalternizadas, presentes em alguns cartazes, foram alvos do incômodo de conservadores, provocando embates para a escola com pais de estudantes e outras pessoas que souberam dos cartazes, inclusive com um vereador da cidade.

Preconceitos e discriminações como problemas para serem tratados na escola emergiram nessa ação. "O que me chamou bastante a atenção foi a capacidade [de o] adolescente estar com um pouco mais de visão diante de tanta intolerância". (Professora Benedita). A partir da leitura

\footnotetext{
3 Tivemos acesso aos cartazes e outras informações sobre a atividade com a professora Benedita e com a coordenação pedagógica da escola.
} 
realizada, percebemos o estímulo da docente ao sentimento de crença no potencial criativo, na capacidade de argumentação e na possibilidade de intervenção social dos alunos. Provocar a sensibilidade pelas questões apontadas era um objetivo. Observaram-se "[...] frases imprevisíveis num lugar ordenado pelas técnicas organizadoras de sistemas”. (CERTEAU, 1994, p. 97). Temas inesperados foram trazidos pelos estudantes e fizeram parte da atividade solicitada.

É interessante saber que o cartaz mais votado pelos estudantes como o que mais os cativou falava sobre o sonho de uma sociedade igualitária. Não mencionamos ainda que esse trabalho se colocava favorável à causa LGBT. Foi um dos cartazes que incomodaram certos membros mais conservadores da comunidade. Em nossa interpretação, participantes da atividade instigam a pensar que não precisamos conservar uma sociedade desigual, incluindo os "valores" depreciativos sustentadores dela.

Mobilizações sociais inserem as problematizações dos preconceitos na pauta dos debates nas universidades e escolas que aparecem em ocasiões específicas, quando essas questões subitamente vêm à tona. "Hoje em dia, é muito falado de discriminação e racismo. Então, a gente sempre tenta dar esse foco, às vezes saindo um pouco do conteúdo. Mesmo sendo de matemática, também converso com os alunos sobre esses assuntos". (Professor Ciro).

Torna-se cada vez mais importante entender e contestar a estigmatização pejorativa dos marginalizados em conhecimentos a respeito deles. Faz-se "[...] necessário penetrar no universo de preconceitos e discriminações que impregna - muitas vezes com caráter difuso, fluido e sutil todas as relações sociais que configuram os contextos em que vivemos". (CANDAU, 2008, p. 53).

Outra iniciativa questionadora de preconceitos e discriminações foi citada pela professora Sandra. Ela solicitou que estudantes dos anos finais do ensino fundamental, com os quais trabalha, participassem de atividades direcionadas a perceber as representações das mulheres. Fez alguns apontamentos históricos da situação da mulher na sociedade e da importância da Lei Maria da Penha. "Os alunos, tanto os meninos quanto as meninas, fotografavam mulheres no cotidiano, em cenas no cotidiano. Não podiam ser selfies, não podia ser foto editada. Aí a gente montou uma exposição". (Professora Sandra).

A maioria das fotos era de pessoas próximas aos estudantes: mães, tias e avós. A docente disse que os alunos se impressionaram com a quantidade de tarefas executadas pelas mulheres retratadas em fotos do dia a dia. O objetivo da atividade era valorizar as mulheres e a discussão da desigualdade de gênero.

Mesmo com esse trabalho no ano anterior à entrevista, houve a subalternização da mulher em falas de estudantes ouvidas pela professora Sandra no ano letivo seguinte. A docente recordou os alunos do trabalho feito por estes no ano anterior com as atividades voltadas ao debate dos preconceitos e discriminações referentes ao gênero. Também foi à direção da escola e relatou o caso. "Eu falei assim: 'Eu acho que, nesse momento, nós precisamos de uma conversa bem séria'. De repente, aquela velha conversa que dizem: 'De homem para homem'. Eu usei esse termo com eles".

Para relatar um preconceito de gênero, a professora emprega uma expressão que denota preconceito de gênero, mesmo involuntariamente. A conversa de homem para homem como o modelo de conversa séria desqualifica o gênero feminino, que acaba situado na falta de seriedade. O machismo está fortemente arraigado e sua manifestação não ocorre sempre de maneira consciente.

Mesmo quando engajados em projetos curriculares para "[...] combater os inúmeros processos de exclusão e/ou de discriminação presentes nas escolas, educadores e alunos continuam produzindo outras tantas formas de discriminação e/ou de exclusão". (FERRAÇO, CARVALHO, 2012 , p. 8). No entanto, continuam sendo importantes reelaborações do currículo voltadas para o 
combate às discriminações e exclusões raciais, de classe, gêneros e sexualidades, entre outras, em busca de maior sensibilização dos sujeitos escolares para essas questões.

\section{INFERÊNCIAS A PARTIR DA PESQUISA REALIZADA}

$\mathrm{Na}$ pesquisa, percebemos que as discriminações se tornam problemas a serem enfrentados pelos professores quando provocam situações pejorativas nos percursos formativos escolares. Os cotidianos das escolas retratados nas falas dos docentes são marcados por práticas discriminatórias referentes ao desempenho escolar, à classe, à aparência física, ao gênero, sexualidade, raça/etnia que desqualificam diferenças entre os sujeitos, mesmo involuntariamente, afetando trajetórias.

Por vezes, o debate sobre as discriminações não está presente na escola por causa de uma forte tradição seletiva do currículo que exclui essa discussão, muito embora os cotidianos escolares também sejam, ocasionalmente, afetados por atividades que visam combater discriminações e preconceitos inferiorizantes a partir de reelaborações curriculares efetuadas em relações e práticas nas escolas.

Observamos que os professores entrevistados intervêm com a finalidade de manter um ambiente mais acolhedor e com menos exclusão de pessoas na trajetória curricular. Estudantes também colaboram nessas iniciativas quando elas acontecem. Uma escola que discute os preconceitos e as discriminações relacionados com as desigualdades colabora para diminuição das agressões dolorosas sofridas pelas alteridades subalternizadas.

Notamos a existência de docentes que se posicionam como elaboradores de estratégias e táticas pedagógicas de enfrentamento às discriminações e exclusões que permeiam os cotidianos escolares, propondo e executando tarefas, projetos de intervenção e ações inclusivas, mesmo que sejam limitadas.

Ações escolares podem contribuir de alguma forma e em alguma medida nos contínuos combates às discriminações e exclusões raciais, de classe, gêneros e sexualidades, produzidas nos percursos históricos e das culturas.

\section{REFERÊNCIAS}

BANDEIRA, Lourdes; BATISTA, Analía Soria. Preconceito e discriminação como expressões de violência. Estudos Feministas, Florianópolis, ano 10, p. 119-141, 1. sem. 2002.

BARROS, Letícia Maria Renault de; BARROS, Maria Elizabeth Barros de. O problema da análise em pesquisa cartográfica. Fractal, Niterói, v. 25, n. 2, p. 373-390, maio/ago., 2013.

BHABHA, Homi K. O local da cultura. 1. ed. Tradução de Myriam Ávila, Eliana Lourenço de Lima Reis e Gláucia Renate Gonçalves. Belo Horizonte: Ed. UFMG, 1998.

BRITO, Marlene Oliveira de; MACHADO, Vitor. Discriminação planejada: a seletividade do currículo oficial paulista para os anos iniciais do ensino fundamental. Contexto \& Educação, Ijuí, ano 33, n. 105, p. 248-276, maio/ago. 2018.

CANDAU, Vera Maria. Direitos humanos, educação e interculturalidade: as tensões entre igualdade e diferença. Revista Brasileira de Educação, Rio de Janeiro, v. 13, n. 37, p. 45-56, jan./abr., 2008.

CERTEAU, Michel de. A invenção do cotidiano: 1. artes de fazer. 1. ed. Tradução de Ephraim Ferreira Alves. Petrópolis: Vozes, 1994. 
FERRAÇO, Carlos Eduardo; ALVES, Nilda. As pesquisas com os cotidianos das escolas: pistas para se pensar a potência das imagensnarrativas na invenção dos currículos e da formação. Espaço do Currículo, João Pessoa, v. 8, n. 3, p. 306-316, set./dez. 2015.

FERRAÇO, Carlos Eduardo; CARVALHO, Janete Magalhães. Currículo, cotidiano e conversações. Revista e-Curriculum, São Paulo, v. 8, n. 2, p. 1-17, ago. 2012.

HALL, Stuart. A centralidade da cultura: notas sobre as revoluções culturais do nosso tempo. Educação e Realidade, Porto Alegre, v. 22, n. 2, p. 15-46, jul./dez., 1997.

KERNER, Ina. Tudo é interseccional? Sobre a relação entre racismo e sexismo. Novos Estudos CEBRAP, São Paulo, n. 93, p. 45-58, jul. 2012.

LOPES, Alice Casimiro; MACEDO, Elizabeth. Teorias de currículo. 1. ed. São Paulo: Cortez, 2011.

OLIVEIRA, Inês Barbosa de. Certeau e as artes de fazer: as noções de uso, tática e trajetória na pesquisa em educação. In: OLIVEIRA, Inês B.; ALVES, Nilda (orgs.). Pesquisa no/do cotidiano das escolas - sobre redes de saberes. Rio de Janeiro: DP\&A, 2001. cap. 3, p. 39-54.

OLIVEIRA, Inês Barbosa de. Currículo e processos de aprendizagemensino: políticas práticas educacionais cotidianas. Curriculo sem Fronteiras, v. 13, n. 3, p. 375-391, set./dez., 2013.

OLIVEIRA, Luiz Fernandes de. A questão étnico-racial na escola a partir das teorizações sociológicas de François Dubet. In: CANDAU, Vera Maria (org.). Didática: questões contemporâneas. Rio de Janeiro: Forma \& Ação, 2009. cap. 8, p. 157-171.

PATTO, Maria Helena Souza. O conceito de cotidianidade em Agnes Heller e a pesquisa em educação. Perspectivas, São Paulo, n. 16, p. 119-141, 1993.

SILVA, Tomaz Tadeu da. Documentos de identidade: uma introdução às teorias do currículo. 2. ed. Belo Horizonte: Autêntica, 2000.

SKLIAR, Carlos. Pedagogia (improvável) da diferença: e se o outro não estivesse aî? Rio de Janeiro: DP\&A, 2003.

SKLIAR, Carlos. Seis perguntas sobre a questão da inclusão ou de como acabar de uma vez por todas com as velhas - e novas - fronteiras em educação! Pro-posições, Campinas, v. 12, n. 2-3, p. 11 21, jul./nov., 2001.

TEDESCO, Silvia Helena; SADE, Christian; CALIMAN, Luciana Vieira. A entrevista na pesquisa cartográfica: a experiência do dizer. Fractal, Niterói, v. 25, n. 2, p. 299-322, maio/ago. 2013.

\section{Informações dos autores}

José Bonifácio Alves da Silva

Fundação Universidade Regional de Blumenau

E-mail: zezao-boni@hotmail.com

ORCID: https://orcid.org/0000-0003-4274-5919

Link Lattes: http://lattes.cnpq.br/0008098470643683 
Gicele Maria Cervi

Fundação Universidade Regional de Blumenau

E-mail: gicele.cervi@gmail.com

ORCID: https://orcid.org/0000-0003-1667-4643

Link Lattes: http://lattes.cnpq.br/3699065025945919 